\title{
Germinação de sementes de Mimosa scabrella Benth. submetidas a diferentes condições de temperatura, armazenamento e tratamentos pré-germinativos
}

\section{Germination of Mimosa scabrella Benth. seeds under different conditions of temperature, storage, and pre-germinative treatments}

\author{
Renata Menegatti1,*, Adelar Mantovani², Márcio Carlos Navroski², Karina Guollo³, \\ Oieler Felipe Vargas² e Aline das Graças de Souza1
}

\begin{abstract}
${ }^{1}$ Universidade Federal de Pelotas, Campus Capão do Leão, Campus Universitário, S/N C.P. 345 Capão do Leão - RS - Brasil, CEP: 96010 900, Pelotas, Rio Grande do Sul, Brasil 2 Universidade do Estado de Santa Catarina, Centro de Ciências Agroveterinárias, Av. Luiz de Camões 2090, Bairro Conta Dinheiro, CEP: 88520-000, Lages, Santa Catarina, Brasil 3 Universidade Tecnológica Federal do Paraná, Campus Pato Branco, Via Conhecimento, Km 1, CEP 85505-390, Pato Branco, PR, Brasil

( ${ }^{\star} E-$-mail: renata.d.menegatti@gmail.com)

http://dx.doi.org/10.19084/RCA16153
\end{abstract}

Recebido/received: 2016.11.20

Recebido em versão revista/received in revised form: 2016.12.14

Aceite/accepted: 2016.12.14

\section{R E S U M O}

Este estudo teve como objetivo avaliar o efeito de diferentes temperaturas, tempo de armazenamento e tratamentos pré-germinativos na quebra de dormência de sementes da leguminosa Mimosa scabrella Benth. O trabalho foi realizado na Universidade do Estado de Santa Catarina, Lages. O delineamento experimental utilizado foi o inteiramente casualizado, e as análises de variância foram efetuadas sob o esquema fatorial 2×2×7 (duas temperaturas, dois períodos de armazenamento e sete tratamentos pré-germinativos). A comparação de médias foi feita pelo teste de Scott-knott, a $5 \%$ de probabilidade. As temperaturas testadas foram constantes de 25 e $30^{\circ} \mathrm{C}$, os períodos de armazenamento foram de zero e oito meses de armazenamento e o tratamento pré-germinativo consistiu em imersão em água a $80^{\circ} \mathrm{C}$ por períodos de 3, 6, 9, 12, 15 e 18 horas. Os resultados obtidos evidenciaram maior porcentagem de germinação das sementes de bracatinga na temperatura de $30^{\circ} \mathrm{C}$, com tratamento pré-germinativo de imersão em água a $80^{\circ} \mathrm{C}$, com posterior permanência durante 3 horas, independente do armazenamento.

Palavras-chave: bracatinga, qualidade fisiológica, sementes florestais.

\begin{abstract}
A B S T R A C T
The objective of this study was to evaluate the effect of temperature, storage time and pre-germination treatments in the germination of Mimosa scabrella Benth seeds. The study was conducted at the University of the State of Santa Catarina, Lages. The experimental design was completely randomized, and analysis of variance was performed under the factorial $2 \times 2 \times 7$ (two temperatures, two periods of storage, and seven pre-germination treatments). The average values were compared by Scott-Knott test at $5 \%$ probability. The temperatures employed were 25 and $30^{\circ} \mathrm{C}$, the storage periods were eight months and no storage and pre-germination treatments were immersion in water at $80^{\circ} \mathrm{C}$ for periods of $3,6,9,12,15$ and 18 hours. The results showed higher germination of seeds bracatinga in temperature $30^{\circ} \mathrm{C}$, regardless of storage, and immersion for 3 hours in water at $80^{\circ} \mathrm{C}$.
\end{abstract}

Keywords: bracatinga, physiological quality, tree seed. 


\section{INTRODUÇÃO}

Mimosa scabrella Benth. é uma espécie pioneira, de ciclo curto e uso múltiplo, pertencente à família Fabaceae e conhecida popularmente como bracatinga. Recentemente, tem tido atenção em amplo espectro de pesquisas no Sul do Brasil (Decezare et al., 2015; Guollo et al., 2016; Menegatti et al., 2016), principalmente por ser utilizada como carvão em diversos processos industriais, no aquecimento de caldeiras, olarias, cerâmicas, paisagismo e outros (Siminski, 2009; Mazuchowski, 2012). A espécie destaca-se pelo rápido crescimento, podendo atingir aproximadamente $20 \mathrm{~m}$ de altura, e diâmetro de até $40 \mathrm{~cm}$ de diâmetro à altura do peito (Catie, 1996; Fabrowski et al., 2005). Atinge a idade reprodutiva aos três anos e tem uma longevidade de aproximadamente 25 anos (Mazuchowski et al., 2014).

A floração inicia-se durante o inverno, de julho até setembro, frutificando de dezembro até março (Embrapa, 1988), dependendo da região. Os frutos, vagem, são secos, deiscentes, e quando maduros adquirem coloração castanho-escura. A colheita das sementes pode ser feita diretamente na árvore, ou no chão através da vibração manual do tronco e copa (Mazuchowski et al., 2014). A extração das sementes pode ser feita manualmente, basta colocar os frutos em saco de aniagem e submetê-los a bateduras (Carvalho et al., 2003).

As sementes de bracatinga apresentam dormência tegumentar, sendo impermeáveis à água (Ahrens, 1981; Bianchetti, 1981; Carpanezzi et al., 1997), desta forma, a germinação é dificultada. Existem diversos métodos para quebrar a dormência tegumentar das sementes de bracatinga, e segundo Bianchetti (1981) e Barazetti e Sccoti (2010) o melhor tratamento para a quebra de dormência das sementes da espécie é a submersão destas em ácido sulfúrico durante quatro minutos, porém tal tratamento, afeta negativamente o desenvolvimento das plântulas, o que pode não ser o mais indicado para a utilização na produção de mudas.

Na literatura são raros os estudos recentes referentes ao efeito da temperatura e do tempo de permanência das sementes no tratamento pré-germinativo (permanência das sementes em água) sob a germinação de sementes de bracatinga, entre eles, podemos citar Bianchetti (1981), Carneiro et al. (1982) e Decezare et al. (2015). Por meio de alguns ensaios Carneiro (1968) utilizando diversos tratamentos para a quebra da dormência das sementes de bracatinga constatou que a imersão em água quente é o método mais eficiente para a quebra de dormência.

Bianchetti (1981) recomenda a imersão das sementes em água à temperatura entre 80 e $96^{\circ} \mathrm{C}$, deixando-se as sementes em repouso nesta água fora do aquecimento, por 18 horas, ainda através de estudos realizados em laboratório, ele concluiu que esse método é o mais vantajoso, tanto pela eficiência na quebra da dormência, quanto pela praticidade de utilização e baixo custo. Decezare et al. (2015) sugerem o mesmo tratamento pré-germinativo, porém por 24 horas de permanência, o que despende maior tempo de trabalho.

Para os viveiristas o conhecimento do tempo ideal despendido para a quebra da dormência das sementes é de significativa importância, visto que quanto mais rápida e uniforme for a germinação das sementes, menos tempo estas permanecem sob condições adversas, aumentando as possibilidades de estabelecimento das plântulas no processo de produção de mudas (Melo et al., 1998).

As sementes com dormência, principalmente causada por tegumento impermeável, possuem alta longevidade (Carvalho et al., 2006), e por isso podem ser armazenadas durante longos períodos (Kageyama e Viana, 1991). Porém, as sementes armazenadas sofrem deteriorações irreversíveis (Marcos Filho, 2005) que causam redução na percentagem de germinação. Desta forma, o conhecimento do tempo de armazenamento adequado para determinada espécie, é imprescindível para a o sucesso do processo de produção de mudas. Outro fator que apresenta influência na germinação das sementes é a temperatura, pois para cada espécie existe uma temperatura ótima na qual o processo de germinação ocorre de forma mais rápida e eficientemente (Bewley e Black, 1982).

Perante o exposto, este trabalho teve como objetivo avaliar o efeito dos diferentes tratamentos pré-germinativos, dos tempos de armazenamento e da temperatura na germinação de sementes de bracatinga. 


\section{MATERIAIS E MÉTODOS}

Os frutos foram colhidos em dez árvores matrizes, localizadas no campus do Centro de Ciências Agroveterinárias (CAV) da Universidade do Estado de Santa Catarina (UDESC), no município de Lages. A colheita foi realizada no ano de 2014, mais precisamente no mês de Janeiro, quando ocorre o início do processo de maturação fisiológica das sementes (os frutos começam a apresentar coloração parda ou castanho-claro), que segundo Carvalho (2002), no estado de Santa Catarina, ocorre entre os meses de dezembro a março.

A colheita dos frutos foi feita diretamente nos ramos da árvore e imediatamente levados para o Laboratório de Ecologia da mesma Universidade e acondicionados à sombra para posterior extração manual das sementes, que consistiu em colocar os frutos em sacos de aniagem e submetê-los a bateduras. As sementes armazenadas por oito meses foram submetidas às condições ambientais do laboratório (sem controle de temperatura eumidade relativa do ar), dentro de sacos plásticos impermeáveis.

Os ensaios de germinação foram realizados de acordo com as instruções para análise de sementes de espécies florestais (Brasil, 2013). As sementes foram colocadas para germinar em rolos de papel germitest, com três folhas, umedecidas com água equivalente a 2,5 vezes o peso do papel. Os rolos foram identificados e mantidos em estufa tipo B.O.D. (Biological Oxygen Demand) pelo período de sete dias (Sanquetta et al., 2013). No final do teste determinou-se a percentagem e velocidade de germinação das sementes, considerando sementes germinadas aquelas que apresentaram a protrusão da radícula de no mínimo dois milímetros (Brasil, 2013).

O ensaio foi instalado seguindo o delineamento inteiramente casualisado, com quatro repetições de 25 sementes e a análise de variância foi efetuada sob o esquema fatorial $2 \times 2 \times 7$. Os fatores referem-se a dois níveis de temperatura $\left(25^{\circ}\right.$ e $\left.30^{\circ} \mathrm{C}\right)$, dois níveis de armazenamento (sem armazenamento e sementes armazenadas durante oito meses), e sete níveis de tratamentos pré-germinativos (imersão em água a $80^{\circ} \mathrm{C}$ por períodos de $3,6,9,12,15$ e 18 horas até atingir a temperatura ambiente, além da testemunha, onde as sementes foram apenas lavadas com água a temperatura ambiente).
Procedeu-se o Teste de Lilliefors para verificar a normalidade dos dados e quando aplicável, as médias observadas foram transformadas em arco seno da raiz quadrada de $x / 100$. Para verificar o nível de significância dos fatores e das suas interações, foi realizado o Teste F. Quando significativas, foram aplicados o teste de médias de Scott-Knott para os fatores qualitativos. A análise estatística foi realizada com o auxílio do software estatístico Assistência Estatística (ASSISTAT 7.6).

\section{RESULTADOS E DISCUSSÃO}

A análise de variância revelou efeito significativo $(p<0,01)$ para o fator armazenamento e períodos pré-germinativos, tanto para porcentagem quanto para a velocidade de germinação das sementes de bracatinga (Quadro 1). Portanto, rejeitou-se a hipótese de nulidade $H 0$, para estes efeitos. Para o fator temperatura, apenas a porcentagem de germinação mostrou diferenças significativas $(\mathrm{p}<0,05)$.

As interações também foram significativas, com exceção daquelas envolvendo temperatura e tratamento pré-germinativo, tanto para a porcentagem quanto para a velocidade de germinação.

Quadro 1 - Valores de F resultantes das análises de variância referentes à porcentagem de germinação (\% G) e índice de velocidade de germinação (IVG) das sementes de Mimosa scabrella Benth. (bracatinga) submetidas a diferentes temperaturas $(T)$, períodos de armazenamento $(A)$ e tratamentos pré-germinativos (PG)

\begin{tabular}{lcc}
\hline FV & \% G & \multicolumn{1}{c}{ IVG } \\
\hline Temperatura (T) & $5.47^{*}$ & $1.20^{\mathrm{ns}}$ \\
Armazenamento (A) & $34.46^{* *}$ & $22.50^{* *}$ \\
Tratamento pré-germinativo (PG) & $70.63^{* *}$ & $69.14^{* *}$ \\
Interação (T x A) & $15.69^{* *}$ & $13.24^{* *}$ \\
Interação (T x PG) & $0.73^{\text {ns }}$ & $1.44^{\text {ns }}$ \\
Interação (A x PG) & $4.31^{* *}$ & $3.81^{* *}$ \\
CV (\%) & 10.41 & 14.04 \\
\hline
\end{tabular}

Nota: ** significativo ao nível de $1 \%$ de probabilidade; *significativo ao nível de $5 \%$ de probabilidade; ns = não significativo; $F V=$ fontes de variação; CV = coeficiente de variação.

A interação entre os fatores temperatura e armazenamento mostrou-se significativa (Quadro 2). Os maiores valores referentes ao percentual germinativo foram constatados para as duas temperaturas 
testadas $\left(25^{\circ}\right.$ e $\left.30^{\circ} \mathrm{C}\right)$, independente do período de armazenamento, apenas as sementes armazenadas por oito meses com germinação a $25^{\circ} \mathrm{C}$ diferiram estatisticamente (comportamento inferior). Pode-se considerar desta forma, que o percentual germinativo das sementes de bracatinga, é indiferente entre as temperaturas de $25^{\circ}$ e $30^{\circ} \mathrm{C}$, até 8 meses de armazenamento.

Ramos e Bianchetti (1992) indicam como melhor temperatura para a germinação de sementes de bracatinga, valores entre $22^{\circ}$ e $26^{\circ} \mathrm{C}$, porém a partir dos dados encontrados neste trabalho, presume-se que esta faixa de temperatura seja eficaz apenas para a germinação de sementes que não foram submetidas ao armazenamento. Em estudos referentes ao potencial germinativo de sementes de bracatinga, Bianchetti et al. (1995) recomenda as temperaturas de $20^{\circ}$ a $36^{\circ} \mathrm{C}$ para melhor desempenho germinativo, apesar de considerarem uma ampla faixa de temperatura, os autores enquadram os $30^{\circ} \mathrm{C}$, também encontrado neste trabalho, como a temperatura ideal para a germinação das sementes de bracatinga, independente do período de armazenamento.

Desta forma, o armazenamento de sementes de bracatinga pelo período de oito meses à temperatura ambiente e posterior germinação a $25^{\circ} \mathrm{C}$, não é indicada, possivelmente em decorrência da perda da viabilidade. De acordo com Reitz et al. (1978) sementes de bracatinga são classificadas como ortodoxas e podem manter sua viabilidade por até três anos. Porém a viabilidade pode ser mantida desde que o armazenamento seja feito em baixas temperaturas.

Quadro 2 - Percentual germinativo de sementes de bracatinga (Mimosa scabrella Benth.) em função da interação entre os fatores temperatura e armazenamento

\begin{tabular}{ccc}
\hline & \multicolumn{2}{c}{ Germinação (\%)* } \\
\hline \multirow{2}{*}{ Temperatura $\left(\mathrm{C}^{\circ}\right)$} & \multicolumn{2}{c}{ Armazenamento } \\
\cline { 2 - 3 } & $\begin{array}{c}\text { Antes do } \\
\text { armazenamento }\end{array}$ & $\begin{array}{c}8 \text { meses de } \\
\text { armazenamento }\end{array}$ \\
\hline 25 & $82 \mathrm{aA}$ & $67 \mathrm{bB}$ \\
30 & $79 \mathrm{aA}$ & $76 \mathrm{aA}$ \\
\hline
\end{tabular}

Nota: Médias não seguidas de mesma letra maiúscula na linha e minúscula na coluna diferem estatisticamente entre si pelo Teste de Scott-knott, ao nível de $5 \%$ de probabilidade.

Pode-se inferir que o armazenamento das sementes em condições naturais (sem controle), como o realizado neste trabalho, pode ter afetado consideravelmente o percentual germinativo das sementes. Isto se dá pelo fato de que o metabolismo das sementes se mantém constante em condições de temperatura e umidade baixas. Portanto indica-se a realização de estudos que avaliem mensalmente sua viabilidade, e desta forma, avaliar diferentes ambientes e embalagens para o armazenamento, buscando a manutenção da qualidade fisiológica.

A interação entre os fatores armazenamento e tratamento pré-germinativo, também foi constatada (Quadro 3), e nota-se que para sementes sem armazenamento, todos os tratamentos pré-germinativos apresentaram alto percentual germinativo, não diferindo estatisticamente entre si. Desta forma, de modo geral a imersão das sementes de bracatinga em água a $80^{\circ} \mathrm{C}$ por 3 horas, independente se armazenadas ou não, mostrou-se a mais indicada para a quebra da dormência, e posterior obtenção de alto percentual germinativo, respectivamente $83 \%$ e $77 \%$. Resultado semelhante ao encontrado por Bianchetti (1981), que obteve uma percentagem de germinação de $75 \%$ em sementes de bracatinga, imersas em água a $80^{\circ} \mathrm{C}$, porém com um tempo muito maior de permanência em água (18 horas).

Estudo realizado por Albrecht (1990) mostra que a imersão das sementes em água $80^{\circ} \mathrm{C}$ durante uma hora, com posterior permanência até atingir a temperatura ambiente, apresentou percentual germinativo de $51 \%$. Considerando os resultados alcançados por Albrecht (1990), e complementando-os com os resultados obtidos neste trabalho, acredita-se que o acréscimo de 2 horas na permanência das sementes em água, possivelmente resultaria em um acréscimo de aproximadamente $30 \%$ do percentual germinativo.

O período de três horas, além de garantir alto desempenho na germinação das sementes de bracatinga, é consideravelmente inferior ao período de 18 ou 24 horas de permanência recomendado por Bianchetti (1981) ou Decezare et al. (2015), respetivamente, e muito utilizado pelos investigadores e produtores de mudas. Este resultado mostra-se significativo e positivo, pois poderá ser utilizado por viveiristas, a fim de reduzir o tempo durante o processo de produção de mudas.

Vale ressaltar que as sementes pertencentes ao tratamento testemunha, ou seja, as que não receberam 
Quadro 3 - Porcentagem de germinação de sementes de bracatinga (Mimosa scabrella Benth.) em função da interação entre os fatores armazenamento (A) e tratamento pré-germinativo (TG)

\begin{tabular}{lccccccccc}
\hline \multicolumn{10}{c}{ Germinação (\%)* } \\
\hline \multirow{8}{*}{ Armazenamento } & \multicolumn{7}{c}{ Tratamento pré-germinativo } \\
\cline { 2 - 9 } & Testemunha & PG 1 & PG 2 & PG 3 & PG 4 & PG 5 & PG 6 \\
\hline Antes do armazenamento & $52 \mathrm{aB}$ & $83 \mathrm{aA}$ & $78 \mathrm{aA}$ & $89 \mathrm{aA}$ & $85 \mathrm{aA}$ & $85 \mathrm{aA}$ & $88 \mathrm{aA}$ \\
& & & & & & & & \\
8 meses de armazenamento & $25 \mathrm{bB}$ & $77 \mathrm{aA}$ & $74 \mathrm{aA}$ & $81 \mathrm{bA}$ & $82 \mathrm{aA}$ & $80 \mathrm{aA}$ & $80 \mathrm{bA}$
\end{tabular}

Nota: PG1: tratamento pré-germinativo em que as sementes foram imersas em água quente a $80^{\circ} \mathrm{C}$, e permaneceram até atingir a temperatura ambiente, por 3 horas; PG2: 6 horas; PG3: 9 horas; PG4: 12 horas; PG5: 15 horas e PG6: 18 horas.

* Médias não seguidas de mesma letra maiúscula na linha e minúscula na coluna diferem estatisticamente entre si pelo Teste de Scott-knott, ao nível de 5\% de probabilidade.

tratamento pré-germinativo, resultaram em percentuais germinativos ligeiramente inferiores aos demais, sugerindo que, é necessário o tratamento para a quebra de dormência em sementes dessa espécie, para a obtenção de alto valor germinativo, de forma rápida e uniforme (Carvalho e Nakagawa, 2000), desempenho este requerido em procedimentos de produção de mudas.

\section{CONCLUSÕES}

A germinação das sementes de bracatinga é favo- recida à temperatura de $30^{\circ} \mathrm{C}$, propiciando valores máximos de germinação, independente do armazenamento, desde que submetidas a tratamentos para a quebra da dormência.

Não é indicado o armazenamento de sementes de bracatinga pelo período de oito meses, em condições de ambiente natural.

A imersão e permanência das sementes em água a $80^{\circ} \mathrm{C}$ durante 3 horas é indicada como tratamento pré-germinativo para superar a dormência causada pela impermeabilidade do tegumento à água, indiferente se forem sementes recém-colhidas ou armazenadas durante oito meses.

\section{REFERÊNCIAS BIBLIOGRÁFICAS}

Ahrens, S. (1981) - Um modelo matemático para volumetria comercial de bracatinga (Mimosa scabrella Benth.). Seminário sobre atualidades e perspectivas florestais, Curitiba, PR. "Bracatinga uma alternativa para reflorestamento". Anais. EMBRAPA-URPFCS, Curitiba, p. 77-90. (EMBRAPA-URPFCS. Documentos, 5).

Albrecht, J.M.F. (1990) - Estudo sobre a germinação de Mimosa scabrella Benth. (bracatinga) e Acacia mearnsii de Wild. (acácia-negra) em função de tratamentos pré-germinativos. Revista Floresta, vol. 20, n.os 1-2, p. 3-4.

Barazetti, V.M. \& Sccoti, M.S.V. (2010) - Quebra de dormência e tipos de substrato para avaliação da qualidade fisiológica de um lote de sementes de bracatinga (Mimosa scabrella Bentham.). Revista Unoesc $\mathcal{E}$ Ciência, vol. 1, n. 1, p. 69-76.

Bewley, J.D. \& Black, M. (1982) - Physiology and biochemistry of seeds in relation to germination. Springer-Verlag, New York, 306 p.

Bianchetti, A. (1981) - Métodos para superar a dormência de sementes de bracatinga (Mimosa scabrella Benth.). Circular Técnica Embrapa: Curitiba, vol. 4, p. 18.

Bianchetti, A.; Ramos, A.; Martins, E.G.; Fowler, J.A.P. \& Alves, V.F. (1995) - Substrato e temperaturas para a germinação de sementes de Bracatinga (Mimosa scabrella). Embrapa, n. 10, p. 1.

Brasil (2013) - Instruções para análise de sementes de espécies florestais. Ministério da Agricultura, Pecuária e Abastecimento, Brasília, 98 p. 
Carneiro, J.G.A. (1968) - Ensaio sobre quebra de dormência de sementes de bracatinga. Congresso Florestal Brasileiro, 1968, Curitiba, PR. Anais. Curitiba, p. 287-288.

Carneiro, R.M.; Almeida Junior, A.R.; Kageyama, P.Y. \& Dias, I.S. (1982) - Importância da dormência das sementes na regeneração da bracatinga - Mimosa scabrella Benth. Circular Técnica. IPEF, Piracicaba, p. 10.

Carpanezzi, A.A.; Pagano, S.N. \& Baggio, A.J. (1997) - Banco de sementes de bracatinga em povoamentos do sistema agroflorestal tradicional de cultivo. Boletim de Pesquisa Florestal, n. 35, p. 3-19.

Carvalho, L.R.; Silva, E.A.A. \& Davide, A.C. (2006) - Classificação de sementes florestais quanto ao comportamento no armazenamento. Revista Brasileira de Sementes, vol. 28, n. 2, p. 15-25. http://dx.doi.org/10.1590/ $\underline{\text { S0101-31222006000200003 }}$

Carvalho, N.M. \& Nakagawa, J. (2000) - Sementes: ciência, tecnologia e produção. 4. ㄹ ed. FUNEP, Jaboticabal, 588 p.

Carvalho, P.E.R.; Medrado, M.J.S. \& Hoeflich, V.A. (2003) - Cultivo da bracatinga. Embrapa Florestas, Colombo, PR, 145 p.

Carvalho, P.E.R. (2002) - Bracatinga. Embrapa Florestas, Colombo, 12 p. (Circular Técnica, 59).

Catie (1996) - Mimosa scabrella. Silvicultura de especies promisorias para producción de leña em America Central: resultados de cinco años de investigación. Centro Agronómico Tropical de Investigación y Enseñanza, Turrialba, p. 205-210.

Decezare, J.C.; Sperandio, N.C. \& Gerber, T. (2015) - Estudos sobre a germinação de sementes de Mimosa scabrella bentham (Bracatinga) em função de tratamento pré-germinativo. Scientific Electronic Archives, vol. 8, n. 3, p. 11-15.

Embrapa (1988) - Zoneamento ecológico para plantios florestais no Estado de Santa Catarina. Centro Nacional de Pesquisa de Florestas EMBRAPA-CNPF, Curitiba, PR, 113 p. (Documentos, 21).

Fabrowski, F.J.; Muñiz, G.B.; Mazza, M.C.M.; Nakashima, T.; Klock, U.; Possamai, J. C. \& Nisgoski, S. (2005) - Anatomia comparativa da madeira das variedades populares da bracatinga (Mimosa scabrella Bentham). Ciência Florestal, vol. 15, n. 1, p. 65-73. http://dx.doi.org/10.5902/198050981824

Guollo, K.; Menegatti, R.D.; Debastiani, A.B.; Possenti, J.C. \& Navroski, M.C. (2016) - Biometria de frutos e sementes e determinação da curva de embebição em sementes de Mimosa scabrella Benth. Revista Cultivando o Saber, vol. 9, p. 1-10.

Kageyama, P.Y. \& Viana, V.M. (1991) - Tecnologia de sementes e grupos ecológicos de espécies arbóreas tropicais. Simpósio Brasileiro sobre tecnologia de sementes florestais, 1989, Atibaia, SP. Anais. Instituto Florestal, Atibaia, p. 197-215.

Marcos Filho, J. (2005) - Fisiologia de sementes de plantas cultivadas. FEALQ, Piracicaba, 495 p.

Mazuchowski, J.Z. (2012) - Sistema de produção de bracatinga Mimosa scabrella Benth. sob técnicas de manejo silvicultural. Tese de Doutorado em Engenharia Florestal. Curitiba, Universidade Federal do Paraná, 193 p.

Mazuchowski, J.Z.; Rech, T.D. \& Toresan, L. (2014) - Bracatinga, Mimosa scabrella Bentham: cultivo, manejo e usos da espécie. 1. Ed. Epagri, Florianópolis, 365 p.

Melo, J.T.; Silva, J.A.; Torres, R.A.A.; Silveira, C.E.S. \& Caldas, L.S. (1998) - Coleta, propagação e desenvolvimento inicial de espécies do cerrado. In: Sano, S. M. \& Almeida, S. P. (Ed.) - Cerrado: ambiente e flora. EMBRAPA/CPAC, Planaltina, p.195-235.

Menegatti, R.D.; Mantovani, A. \& Navroski, M.C. (2016) - Parâmetros genéticos para caracteres de crescimento inicial de progênies de bracatinga em Lages, SC. Pesquisa Florestal Brasileira, vol. 36, n. 87, p. 235-243. http://dx.doi.org/10.4336/2016.pfb.36.87.1003

Ramos, A. \& Bianchetti, A. (1992) - Viabilidade de lotes de sementes de bracatinga-comum (Mimosa scabrella Benth.) e de bracatinga-argentina (Mimosa scabrella var. aspericarpa) após o teste de envelhecimento precoce. Boletim de Pesquisa Florestal, vol. 24-25, p. 79-82.

Reitz, R.; Klein, R.M. \& Reis, A. (1978) - Bracatinga. Sellowia, vol. 28-30, p. 114-118.

Sanquetta, C.R.; Miranda, D.L.C.; Corte, A.P.D.; Mognon, F. \& Sanquetta, M.N.I. (2013) - Potencial alelopático de Merostachys skvortzovii Sendulsky sobre a germinação de Mimosa scabrella Benth. Enciclopédia biosfera, vol. 9, n. 17, p. 10.

Siminski, A. (2009) - Floresta do Futuro: conhecimento, valorização e perspectiva de uso das formações florestais secundárias no estado de Santa Catarina. Tese de Doutorado em Recursos Genéticos Vegetais. Florianópolis, Universidade Federal de Santa Catarina, Florianópolis, 153 p. 